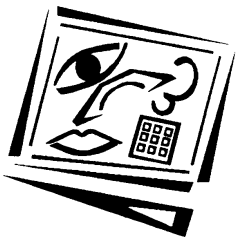

\title{
Informing one-to-one computing in primary schools: Student use of netbooks
}

\author{
Kevin Larkin \\ University of Southern Queensland \\ Glenn Finger \\ Griffith University
}

\begin{abstract}
Although one-to-one laptop programs are being introduced in many schools, minimal research has been conducted regarding their effectiveness in primary schools. Evidence-based research is needed to inform significant funding, deployment and student use of computers. This article analyses key findings from a study conducted in four Year 7 classrooms in which students were provided with netbook computers as an alternative to more expensive laptop computers. Variable access was provided to students including computer to student ratios of one-to-one and one-to-two. Findings indicated that increased access to the netbook computers resulted in increases in computer usage by these students, compared with their minimal use of computers before the study. However, despite the increased access, actual computer usage remained limited. The article reports that factors contributing to the minimal use of computers included individual teacher agency, a crowded curriculum, and the historical use of computers. Implications for policy and practice are suggested.
\end{abstract}

\section{Introduction: Investigating one-to-one computing}

Since the introduction of information and communication technologies (ICT) in schools in the early 1980s, there have been continual and dynamic changes in the technologies available. Accompanying these developments have been attempts to explore how such technologies have been used in schools to enhance student learning. More than 30 years ago, few educators could have imagined the technological advances in the capacity and applications of personal computers, the Internet, and ICT such as interactive whiteboards (IWBs). These changes in capacity have also been evident in improved affordability, which has been reflected in the movement towards greater access by students to computers aimed at providing one-to-one access. In an Australian context this is evident in the supply of one-to-one computing as part of the Digital Education Revolution. The key driver of this research is the determination of the range of factors that influence the relationship between one-to-one access to netbooks and their actual use by students?

Data collected in this research suggest that the one-to-one or one-to-two availability of computers to students did not result in significant use of the computers in terms of time used. The four classrooms received the netbook computers in four different patterns of access: 
1. Class A. Ratio of one-to-one student to netbook access - five days per week for six weeks;

2. Class B. Ratio of one-to-one student to netbook access - three days per week for ten weeks;

3. Class C. Ratio of one-to-two student to netbook access - five days per week for six weeks; and,

4. Class D. Ratio of one-to-one student to netbook access - three days per week for ten weeks.

Although reasonably well resourced through general Federal and State education funding, major ICT initiatives in the school studied are funded via parent levies. The school is ineligible for ICT funding from either the Digital Education Revolution or from Education Queensland systemic funding. The lack of appropriate funding for ICT resources in Catholic primary schools is a key consideration when making decisions regarding the deployment of one-to-one computing.

Russell, Bebell and Higgins (2004) examined whether or not varying computer ratios in elementary classrooms changed the student experience of laptop usage. They studied two classrooms, which were permanently equipped with one laptop for each student, and five other classrooms that shared a cart of laptops to create a one-to-one laptop environment on a temporary basis. That is, these classrooms received the laptops for one week every five weeks. They sought to determine the extent to which this strategy provided a temporary, computer-rich learning environment that was comparable to a setting in which students were provided with their own laptop on a permanent basis. Their research indicated that, although increasing access to computers where each student had his or her own laptop in school would expectedly lead to increased computer use, the magnitude of the difference in computer use was quite dramatic. Whereas students in the shared classrooms reported using computers during class time for between ' 15 minutes or less' and '15 to 60 minutes' a day, students in the oneto-one classrooms reported computer usage of between '1-2 hours per day' and 'over 2 hours per day' (Russell, Bebell \& Higgins, 2004). The permanent one-to-one classrooms provided several advantages over the temporary one-to-one classrooms. In permanent one-to-one classrooms, students used computers more across the curriculum and the authors also noted a difference in the quality of teacher instruction in the one-to-one classrooms with less large-group instruction than in the temporary one-to-one classrooms.

Although becoming more prominent in schools, some authors suggest that there are concerns over the effectiveness of the high cost of one-to-one computing programs, with increasing resistance by some parents, school administrators, and educational bureaucracies to their implementation (Cuban, 2006; Lei \& Zhao, 2008). At the crux of the issue is the debate as to whether or not one-to-one computer programs, which come at a significant cost, have resulted in improved educational outcomes for students (Romeo \& Walker, 2002). Despite the apparent need for research in one-toone computing, research into the educational uses and student outcomes of laptop programs is still in its infancy (Russell, et al., 2004) and aside from project evaluations, independent research on one-to-one computing is still minimal (Penuel, 2006). Furthermore, evidence-based approaches to inform effective and informed decision making are limited as much of the evidence presented about the benefits or otherwise of laptop programs has been largely anecdotal in nature (Newhouse, 1997; Newhouse \& Rennie, 2001). Those responsible for determining educational policy require more 
evidence of the benefits of one-to-one computing programs for learning and teaching (Grimes \& Warschauer, 2008).

\section{Why research is needed for determining actual computer usage in one-to-one environments}

As indicated, one-to-one laptop programs, whereby a computer is available for each student, represent an important, contemporary initiative in the field of educational technology. This is in no small part due to their increased popularity and also their perceived potential to bridge the digital and didactic divide that currently exists in schools (Mouza, 2008). This interest is particularly evident in a plethora of one-to-one initiatives, in the USA, including State-wide deployment to Year Eight and Nine students in Maine (Gravelle, 2003), widespread use in Florida (Dawson, Cavanaugh \& Ritzhaupt, 2008; 2009), and Pennsylvania (Zucker \& Hug, 2008). Such initiatives are also apparent in Australia, in particular through the Digital Education Revolution Secondary Schools Laptop Program (Department of Education, 2008). A component of this 'revolution' has been the planned distribution of laptop computers to all Year 9-12 students in Australian secondary schools to enable the 'digital education revolution'.

As a consequence of the national scale of the Digital Education Revolution laptop program, and the broader political and educational interest in one-to-one computing, the need for contemporary Australian research into one-to-one computing to better inform further Federal and State policymakers is necessary. Given the competing demands for resources in schools, research is needed to inform schools regarding the most effective deployment of funds to enable sustainable models of student access to computers, and their most effective use by students for learning (Oxley, 2008). This article presents the findings of contemporary Australian research, which extends on the work of Russell et al. (2004) by establishing four different patterns of computer access to determine the impact of these patterns on student computer use and suggests that regardless of access patterns, overall student usage of the computers was minimal.

\section{Synthesis of research involving one-to-one computer usage}

Although substantial research into computer usage in classrooms has been conducted (Albion, 1999; Gravelle, 2003; Silvernail \& Lane, 2004), the interest in school based ICT, more recently, has focused on the implementation of one-to-one computing programs (see Bateman \& Oakley, 2009; Franklin, 2007; Penuel, 2006). In this article, one-to-one computing is defined as the availability of a mobile, wireless enabled learning device for each student in a class. Liang, et al. (2005) suggest that a number of components are generally present for a classroom to be described as a one-to-one computing environment. Integral to the concept is that each student has access to a device and that there is a device management system to safely store and recharge the devices when they are not in use. In order to facilitate shared access to resources, and also to demonstrate the outcomes of learning, server space and a data projector are recommended.

\section{Possibilities enabled by one-to-one computing access}

From theoretical and educational perspectives, research suggests that more widespread access to computers makes it possible for students and teachers in schools to move from occasional, supplemental use of computers for instruction to more frequent, integral use of computers across a multitude of settings (Albion, 1999; Lin \& 
Wu, 2010; Rockman, 2003;). This is because teachers and students can begin to conceive of computers as a tool, which is as available to use as pens, paper, and desks in current school classrooms. Beyond facilitating more frequent use of computers in class, enabling better student access to computers can provide students with more equitable access to resources and learning opportunities. Providing students with wireless enabled computing devices gives all students and teachers the ability to use up to date learning resources that before were available only to those who lived close to a library or benefited from school budgets that allowed for regular purchases of new textbooks (Penuel, et al., 2002). However, the set of ideals noted above are a proposition to be investigated rather than an account of what is occurring in various classrooms operating under a range of different circumstances.

Findings from research conducted in one-to-one laptop computing environments mirror many of the findings of previous studies on the use of computers in other than one-to-one contexts. These findings suggest that one-to-one computing leads to changes to teacher pedagogy, including:

- more student centred approaches (Donovan, Hartley \& Strudler, 2007; Swan, Hooft, Kratcoski \& Unger, 2005; Zucker \& Hug, 2008);

- flexible and constructivist teaching styles (Mouza, 2008; Rockman, 2003; Zucker, 2004); and

- delivery of learning episodes which are more project oriented and inquiry based (Swan, Hooft, Kratcoski \& Schenker, 2007).

In regards to student learning, research has shown benefits through:

- increased media literacy (Hill \& Reeves, 2002; Rockman, 2003);

- improved writing (Gulek \& Demirtas, 2005; Mouza, 2008; Ricci, 1999; Rockman, 2003; Russell, Bebell \& Higgins, 2004); and

- increased scores on standardised tests (Gulek \& Demirtas, 2005; Stevenson, 1998).

In terms of a broader positive impact on student performance, other positive effects of ubiquitous laptop computing on students include:

- increased motivation (Mouza, 2008; Ricci, 1999; Russell, et al., 2004; Zucker \& McGhee, 2005);

- improved student engagement (Rockman, 1998; Silvernail \& Lane, 2004);

- decreased disciplinary problems (Silvernail \& Lane, 2004); and

- improved school attendance (Stevenson, 1998).

Students utilising one-to-one laptops were also found to be better organised (Lowther, Ross \& Morrison, 2003) and more independent in their learning (Ricci, 1999; Zucker \& McGhee, 2005). Harris and Smith (2004) noted social and emotional benefits for special needs students who utilised one-to-one laptops. Hounshell, Hill and Swofford (2002) reported improved performance from minority students involved in a one-to-one laptop program, while Lin and Wu (2010) elsewhere reported improvements in learning English.

\section{Factors influencing computer usage in classrooms}

Previous research on computers in schools (see Albion, 1999; Franklin, 2007) has noted a range of factors influencing computer usage including wireless connectivity, 
professional development, software, infrastructure, and pedagogical preferences of teachers. We suggest that these factors can be categorised into two domains using Ertmer's (1999) classification of First or Second order barriers. First order barriers relate more closely to the physical computing environment and include connectivity and the availability of computers. Second order barriers refer to the personal agency of the people involved in computing environments and include ICT competency and pedagogical approaches to computer usage. Due to the strong technical infrastructure in place at the research school, first order barriers identified in other studies (Albion, 1999; Bateman \& Oakley, 2009) were largely eliminated. Consequently, this article, in summarising findings of the study of netbook use by students, focuses on a range of human factors, including the human response to the altered physical environment, which helped to determine computer usage.

Although the teachers in this research will operate within a robust technical infrastructure, this, of itself, does not guarantee that the netbooks will be integrated into the curriculum. For instance, Penuel (2006) noted that even the perception among teachers, that there may be limited access to timely technical support from schoolbased or district staff, can be enough to hinder their computer usage. As indicated above, concerns surrounding computer implementation, whether perceived or real, are often intrinsic and are referred to here as second order barriers (Ertmer, 1999). Research into specific technological innovations seems to suggest that many teachers experience difficulty in implementation (Franklin, 2007), particularly in relation to the implementation of one-to-one computing programs (Larkin \& Finger, 2010). Teacher concerns regarding such innovation appear to cluster around the two themes of curriculum and behaviour management. Significant barriers to computer use in elementary American schools, as perceived by the teachers, included too much curriculum to cover, lack of time in their daily schedule, and high stakes, standardised testing. These factors are explored in this research. Other perceived barriers to the successful use of laptops include an anticipated increase in teacher workload (Zucker \& McGhee, 2005) and concerns related to how teaching styles would need to be adapted to effectively utilise the computers (Penuel, 2006).

Perceptions regarding the usefulness of the laptops in achieving curriculum outcomes are a factor for some teachers in determining computer usage levels. Sarama, Clements and Henry (1998) suggest that a misalignment between curriculum and ICT resulted in diminished use. The characteristics of individual teachers also impacted on the level of implementation and included:

- their pedagogical approach (Watson \& Tinsley, cited in Penuel, 2006);

- confidence or feelings of preparedness to use computers (NCES, 2000);

- subject-matter expertise (Penuel, 2006);

- ability to link laptop use to learning outcomes and standards (Newhouse \& Rennie, 2001); and

- level of technological, pedagogical content knowledge [TPACK] (Mishra \& Koehler, 2006).

Research suggests that the teachers who most utilised the laptops were those who preferred to implement a constructivist pedagogy (Becker, 2000; Vannatta \& Fordham, 2004), and those who were willing to change their teaching philosophy and beliefs (Vannatta \& Fordham, 2004). We suggest that the second order barriers noted above are evident in any computing environment but become further magnified in one-toone environments such as the one analysed here. 


\section{Method}

As this research utilised activity theory as the conceptual framework underpinning both the research methodology and also the latter discussion of the findings, it is appropriate to use a 'mixed method' (Onwuegbuzie, 2002) approach. Such an approach facilitated the investigation, at a deeper level, of the beliefs and values of the teachers and students in this study and how these affected netbook usage. Data used to support the arguments in this article were collected by classroom observations, semi-structured interviews, student forums and surveys, and via the use of data logging software pre-installed on each computer. As data logging software has been utilised sparingly in previous research (Swan, et al., 2005), it is necessary to briefly outline how the direct data collection from the computers was achieved.

The participants in the study were the four Year Seven teachers and the students in their classes. The study took place over the course of a school year. The school had decided to purchase a set of netbooks as a trial to test their appropriateness for Middle Years students. If the trial was successful the school intended to purchase a class set of netbooks for students in Years 5 and 6 . Each of the participants received an information package outlining what was expected of them as participants and student participants also required parental approval. The study received ethical clearance and pseudonyms were used for all participants.

\section{Data logging software}

Although anecdotal information on computer usage, in terms of duration, was gathered via observations and interviews, in order to more accurately report on computer usage it was preferable to gather data directly from each netbook. This provided a more reliable method of collecting usage data and removed the need to rely on self-reports of usage, a method used in other computer studies (Bateman \& Oakley, 2009; Dawson, et al., 2008/2009; Dunleavy, Dexter, \& Heinecke, 2007; Zucker \& McGhee, 2005) in which data on computer usage were collected. The primary data collection device used here was a computer script, which recorded start-up, logon, logoff, and shutdown events. This data, collected daily from 32 netbooks, was automatically forwarded to the lead researcher in spreadsheet format. At the conclusion of each day, data were manually checked and reformatted in a spreadsheet for ease of analysis.

In order to validate that activity was occurring on the netbooks, and that they were not just logged on but unused, a second recording tool, SpyKeylogger was installed on each computer. This tool collected information on every keystroke and thus provided a wealth of information indicating precisely how the students used the netbooks. SpyKeylogger also functioned as a pro-active research tool in that it provided entry points into the experiences of the students. For ethical reasons, the students and teachers were aware that the software was installed on each computer. To further protect identity, no individuals were identified by the data collected as the data were aggregated for analysis. The keystroke data collected is only used in this article as a means of verifying actual usage times as reported in the logon / logoff scripts.

\section{Findings}

It is necessary to contextualise the findings of this research by briefly outlining computer usage prior to the netbook deployment. Each of the four Year Seven 
classrooms had one designated teacher's computer, which was located on the teacher's desk. Students were occasionally allowed to use the teacher's computer. Each classroom also had three or four desktop computers designated for student use. The data collected from the 80 observation periods conducted prior to netbook usage indicated that computer usage, across the four classrooms, was negligible. Only 15 of the 80 unscheduled observation periods showed any evidence of any computer use. Expressed as a percentage, computer usage was evident on only $18.75 \%$ of the classroom observation visits. These observations were confirmed by comments from students in the project who indicated that the classroom computers were used infrequently. Student comments included:

If we want to type things up to hand in we just use the computers at home. (Bob, Student, Class D, July, 2009)

I use them once every two weeks. (Jim, Student, Class D, July 2009)

I get to use them probably once a week to once a fortnight. (Joe, Student, Class C, August, 2009)

In the event that more computer usage was required, the teachers would send students to other classrooms throughout the school to complete their work on the computers in these rooms.

We don't have enough time for everyone to get on the four computers in the classroom unless we are sent to different classrooms to finish on their computers. (Bob, Student, Class D, August 2009).

Classroom observation, interview and survey data all indicate that much of the computer work currently completed at school by students could be more efficiently completed at home (see Finger \& Sun, 2010. When compared with the level of computer use prior to their introduction, computer usage for the students in each class increased significantly as a result of the availability of the netbooks. Computer usage increased from an average of 30 minutes per student per week without the netbooks to between 60-90 minutes average usage per student per day with the netbooks. This represented a tenfold increase in computer usage. The students and teachers spoke positively of the increased access to computers:

The netbooks have been a massive boost to the kids and to computer usage by the kids. (Vernon, Teacher, Class A, June 2009)

It's useful having the netbooks, because they allow us to do our assignment work in the classroom without having to fight for the computers that we have if we are unable to go to the computer lab. (Student, Class D, October 2009)

This increase in usage was relatively consistent across all four classrooms regardless of their pattern of access and hence it is not simply an effect of teacher preference. The data also indicated that, regardless of whether the class had one-to-one or one-to-two access, the two classrooms with three days per week access over ten weeks reported higher levels of netbook use.

Even just having the sixteen is a massive increase in computing access and it changed the way I did things Neville. (Teacher, Class C, May 2009)

Although the availability of the netbooks resulted in a significant increase in usage, as compared to computer usage prior to their deployment, in relation to the overall 
availability of the netbooks (300 minutes per day), usage was low across the four classrooms, as displayed in Figures 1 and 2. As two of the classes had access to computers in a one-to-two ratio, the usage times indicate netbook usage times rather than individual student usage times.

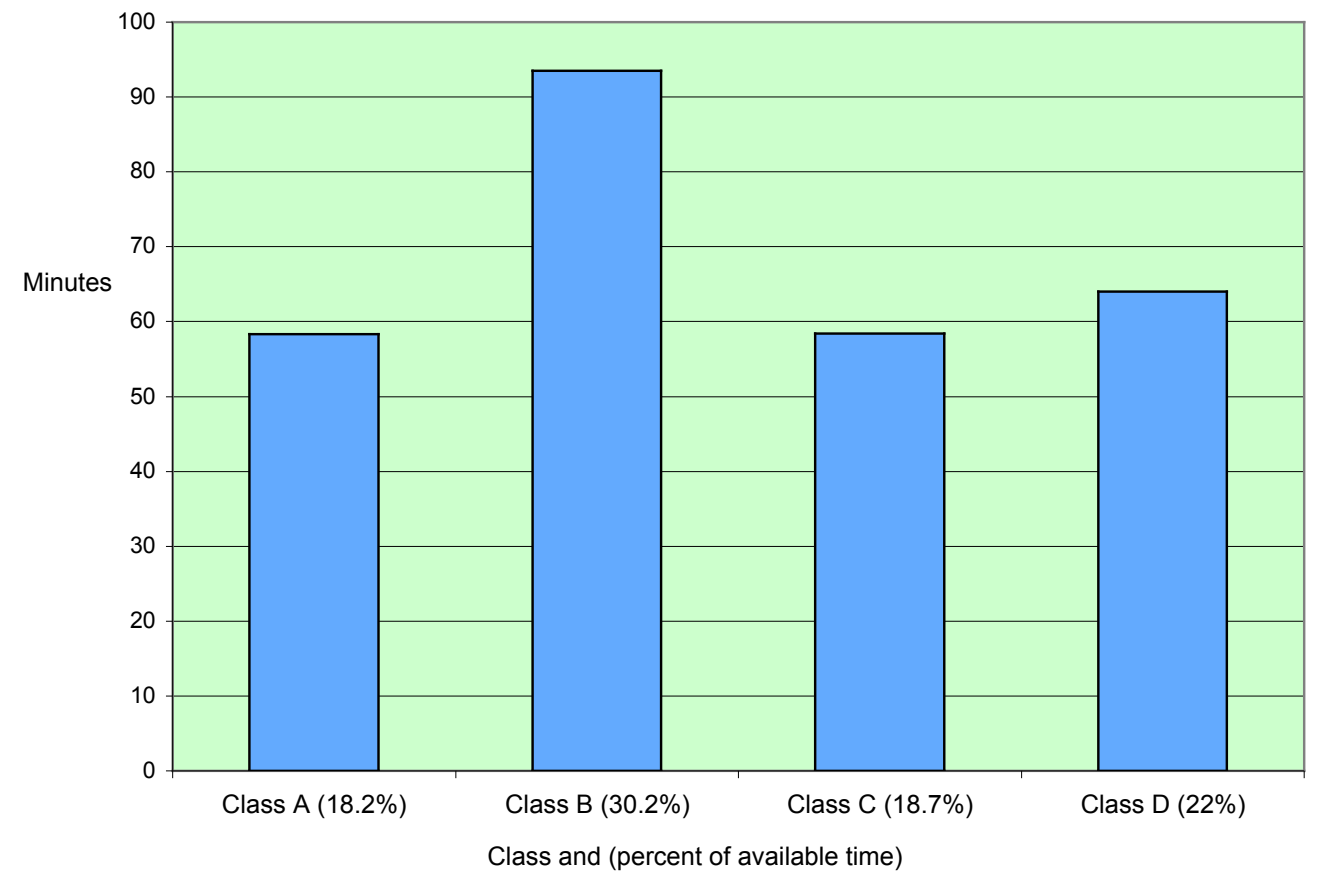

Figure 1: Daily netbook usage (in minutes, and as a percentage of available time)

In some instances, two or more students worked collaboratively on the one netbook, on other occasions, half the students worked individually on the netbooks while the other half completed a non-netbook activity. The predominate mode of use in the classes with one-to-one access was one student per netbook, that is, there were very few occasions that netbooks were left in the trolley and students shared devices to work collaboratively on a task or that some students used netbooks and some students worked on a non-netbook activity.

Daily netbook usage per class in terms of usage time and also as a percentage of available time, as shown in Figure 1, illustrates that, whilst the netbooks were available for 5 hours (300 minutes) per day, the average usage per netbook per day were as follows: Class A (Average daily usage was 54.5 minutes or $18.2 \%$ of the school day; Class B (Average daily usage was 90.4 minutes or 30.2\%); Class C (Average daily usage was 56.1 minutes or 18.7\%); and Class D (Average daily usage was 65.0 minutes or $22 \%)$.

Data presented thus far indicate that the average use of the netbooks was approximately 60 minutes per day for three of the classes and just over 90 minutes per day for the fourth class. Over the course of the 30 days, usage fluctuated. On some days, the netbooks were not used and on other days they were used for sustained 
periods of time. Figure 2 presents data, which indicates the variety of daily usage across all four classrooms. For example, netbooks were used for less than 30 minutes a day for $15 \%$ of the occasions they were used.

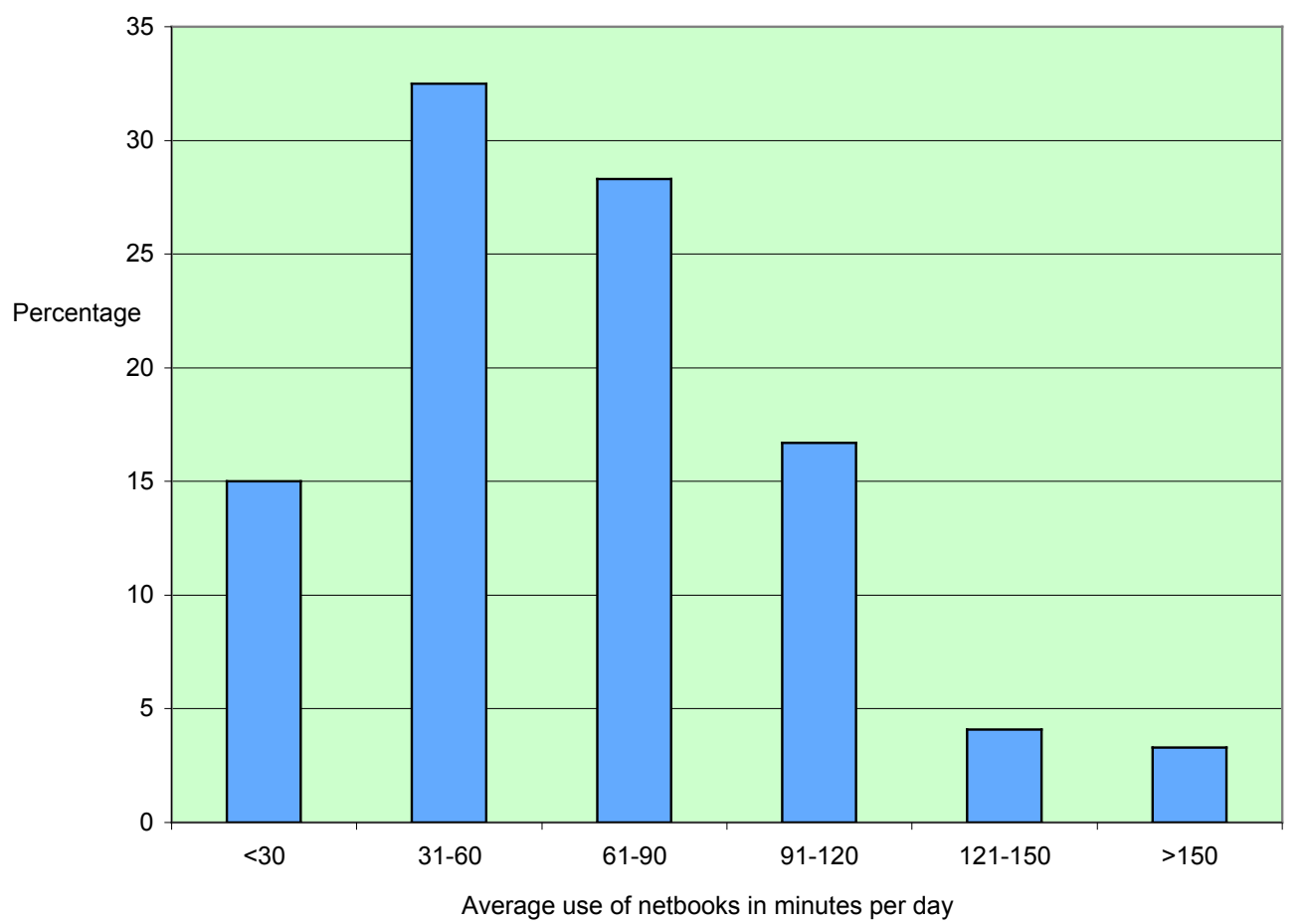

Figure 2: Distribution of netbook usage across the cohort

The data presented in Figure 3 indicates that the predominant daily use of netbooks was between 30 minutes and 90 minutes $(61 \%)$ with the devices used between 30 and 60 minutes, $33 \%$ of the time. On many occasions, the netbooks were only used once per day. In these instances the percentages depicted in Figure 3 represent a single session of usage for that day. There were minimal occasions when the devices were used for more than 2 hours in a day, but a considerable number of occasions when they were used for less than 30 minutes per day. The rare occasions of more than 2 hours use occurred on days where sport or other scheduled events were cancelled and the teachers had time to catch up on 'missed' classroom time.

From the data graphically presented in Figures 1 and 2, it is clear that one-to-one or one-to-two access to computers did not result in substantial computing use of the netbooks by these students. Despite the significant increase in computing access available to students, actual computer usage was very limited. As illustrated in Figure 2 , the range of usage, as a percentage of available time, was $19-31 \%$ with $22.5 \%$ being the mean daily usage across the four classes. This indicates that the devices were only utilised for approximately one-fifth of the available time in 3 of the classrooms and one third of the available time in the fourth classroom during the 30-day trial. These findings are comparable with the findings of Russell, et al., (2004) who reported usage of 15-60 minutes per day in classrooms, which shared computer access, and usage of between 1-2 hours in the one-to-one classrooms. The data presented here on computer 
usage are at the lower end of usage time when compared to those reported by Bateman and Oakley (2009). The primary factors contributing to the level of usage in this project relate to three themes; i) the Technological, Pedagogical and Content Knowledge (TPACK) level of the teachers; ii) lack of time due to a crowded curriculum; and iii) the historicity of tool use. These three key themes are discussed in the following section.

\section{Discussion}

\section{TPACK capabilities and their impact on netbook usage}

The Technological, Pedagogical and Content Knowledge (TPACK) model (Mishra \& Koehler, 2006) attempts to capture some of the essential qualities of knowledge required by teachers which enables them to integrate technology into their practice. Central to this framework is the complex interplay of three primary forms of knowledge. In this model, ICT is considered as a subset of Technological Knowledge. In this conceptualisation, teachers are identified as autonomous agents with power to significantly influence the appropriate integration of ICT into education and to transform the learning experience of students. Mishra and Koehler (2006) suggest that to integrate ICT successfully into classrooms, teachers need to incorporate the three domains of teachers' knowledge: i) knowledge of the curriculum content which the students are required to learn; ii) knowledge of age appropriate ways in which to teach this knowledge; and iii) knowledge as to how technology may be used to facilitate this process.

Jamieson-Proctor, Finger and Albion (2010) note that teachers are well equipped to deliver curriculum content in pedagogically appropriate ways, thus demonstrating Pedagogical Content Knowledge (PCK), but suggest that the Technological Knowledge (TK) component of TPACK is less strong. This perspective was clearly evident in discussions with teachers in this research who each commented that they would have liked to have completed a greater range of activities with the students, but were restricted in doing so by the time constraints noted above and also by a self-identified lack of knowledge of what could be done with the netbooks to enhance the learning experience of the students. For example,

I guess I was limited in what I could do and I would like to learn more. I need to know more as to how to use ICT for teaching using different programs which is why I have signed up for that in-service later in the year. (Vernon, Teacher, Class A, April 2009)

Whilst all four teachers recognised the benefits of the netbooks to engage students, and also in making many teaching tasks more efficient, they also acknowledged that it takes time to learn how to teach well when every student has a computer (Zucker \& Hug, 2008). The acknowledgment by the teachers that they lacked Technological Knowledge had implications for the learning of students, particularly in light of the deployment of significant numbers of computers into these classrooms. These implications include: the use of computers to enhance creativity and thinking skills (both required by the National Curriculum); the opportunity to use the computers across a range of curriculum areas rather than just for word processing; and the use of computers to foster greater home-school links so that students can continue their learning online at home. A clear indication from the teachers is that, in order to take advantage of the potential of one-to-one access to support student learning, the Technological Knowledge component of the teaching practice of many teachers needs to be enhanced. 
The difficulties of integrating computers, including the lack of Technological Knowledge and the individual philosophy of the teachers in relation to ICT usage, were exacerbated by the arrival of substantial numbers of computers, which were to be incorporated into the classroom environment. These devices caused a disruption to the previously established classroom environments and the response of the teachers towards this disruption was a critical factor in the resultant level of netbook usage.

It would appear from an analysis of the usage data, that netbooks were not considered as integral to the educational practice of these teachers. As a consequence of this decision, a tension results as the netbooks became an additional element to be slotted into what the teachers were already doing (rather than being an accepted component of the system such as desks or pens, or textbooks). This observation complements findings from other research (Bateman \& Oakley, 2009; Penuel, 2006) which suggest that computer usage in one-to-one computing environments is strongly correlated with how closely that usage can be aligned with both the pedagogical position of the teacher and also with the current curriculum requirements. For Neville and Jasmine (Teachers Class C and D), the netbooks were not critical for learning and they could largely operate equally well without them.

If the kids need access we go to the lab or we borrow some of the netbooks from Jasmine but it is early in the term so we don't have a lot of use for them so I haven't been chasing them so hard. (Neville, Teacher, Class C, October 2009)

I think I am lucky with the timing of them as we are almost at the end of the year and the tasks that they still have to complete do not really need a lot of computer access. So in that sense I don't need them. (Jasmine, Teacher, Class D, October 2009)

This attitude to computer usage can minimise improvements in student outcomes as their potential for any widespread effect on teaching and learning is co-opted, diluted, and ultimately diminished (Weston \& Bain, 2010). In addition to the attitude of the teachers towards using the netbooks, a tension evident in the use of the netbooks was the pressure of meeting curriculum demands and how the netbooks either assisted or detracted from meeting these demands.

\section{The crowded curriculum}

The experience of teaching in Year 7 classrooms is that significant amounts of direct teaching contact with a class of students is lost due to reasons including non-contact release time, planning days, school and year level assemblies, inter and intra school sport commitments, and extra-curricula or school leadership activities. These interruptions are exacerbated in this particular research context due to the decision of the teachers to implement mathematics groups (students were organised into ability groups for mathematics for four, 1 hour lessons per week), and by rotational key learning area (KLA) activities whereby, every Wednesday, each teacher taught the same 1 hour KLA based lesson. Vernon calculated that each teacher only had face to face contact with their 'home' class for just over three days per week. The other teachers agreed with this assessment.

The timetable does not allow full time use of the computers because Wednesday is out due to rotations and Friday is out because of sport so even getting three days is hard enough. (Wendy, Teacher, Class B, June 2009) 
Today we had Library, Maths, French, emptied and returned the paper bins, Music. After lunch we have to do the rubbish bins!" (Jasmine, Teacher, Class D, February 2009)

In visiting the classrooms during the project it was a common occurrence to witness these interruptions or to discover that smaller groups of students were absent from the classroom completing individual or small group elective activities such as piano, band or speech and drama. As a consequence of these interruptions, opportunities when all of the students were present were precious to the teachers and often precluded computer use.

Compounding the 'usual' disruptions to the school week noted above, the two additional factors in this research which contributed to why the netbooks were most often used for between 30 minutes to 90 minutes per day, were mathematics groups and KLA specialisations. Both of these activities meant that teachers were not with their 'home' class during these times and this impacted substantially on netbook usage. Whilst the teachers were able to use the netbooks during these activities, this option was not exercised to any significant extent by any of the teachers during their respective 30-day period of access. Reasons cited for this lack of use included: the size of the mathematics group in relation to availability of netbooks; lack of knowledge as to how to use the netbooks in specific content areas such as Science or Studies of Society and Environment (SOSE); too much curriculum to cover in the hour dedicated to the specific KLA; and assessment requirements for the KLA not conducive to the netbooks. These reasons coincide with the factors suggested by Franklin (2007) for low computer usage in American schools. It is apparent in this environment, that the teachers perceived the computers as an additional element to be included in the daily activity in the classroom and that to facilitate their use would require a change to their pedagogic and organisational practice and also the broader pedagogic practices of the school. This pedagogic barrier to greater use in the classroom was conceptualised earlier in terms of the TPACK level of the teachers.

\section{Historicity of tool use}

A final consideration in an examination of factors contributing to low levels of netbook usage, and one which was evident independent of the netbook pattern of access, pertains to the 'historicity' inherent in the use of computers as an educational 'tool'. Because of their physical and mental attributes, tools shape both the external behaviour of subjects as well as their internal mental processes. Any tool is, at the same time, both enabling and limiting; it empowers the subject in the transformation process with the historically collected experience and skill 'crystallised' to it (Kuutti, 1996), but at the same time can limit the use of the tool to the historical ways in which it has been previously used. In relation to computer usage, these historical factors include the pedagogical preference of the teachers, their prior experience with computers, and the structure of curriculum and assessment tasks (see Buell, 2003). Tensions have always been present in relation to computer use in classrooms (for example, enhanced access or how to incorporate their use into the curriculum). However, the past experience of computer use by the four teachers in this project has largely been of computer use being supplementary, or even extraneous, to their pedagogical practice The availability of a large number of netbooks challenged this notion.

The initial response of the teachers, in their use of the netbooks, was to attempt to use them in the same manner as they had historically used their classroom computers: that 
is, the production of a range of artefacts (such as typed stories) to demonstrate student learning. This resulted in a tension for the teachers as they resolved how to achieve their historically established educational goals whilst incorporating netbook usage. In some cases, rather than developing new activities in light of the availability of the netbooks, an existing learning activity was selected and the use of the netbooks imposed over the top of this activity. Alternatively, activities were deliberately chosen, not necessarily for educational reasons but only because they could incorporate netbook use.

I would use them when the circumstances arose if they were there all year. Now I am planning circumstances just to more often use them. (Neville, Teacher, Class C, May 2009)

The potential of the netbooks to impact on student learning was also limited by historicity of pedagogic practice. For example, curriculum and assessment rules, which prescribe what is to be taught and how it is to be reported, constrained the use of netbooks. This was evident during the netbook usage period when Vernon wanted the students to submit their work electronically rather than in hard copy. He was prevented from doing so by a school requirement that the students prepare a paper based portfolio of their work for the parents to view during Parent Teacher interviews. As a consequence of this historically constructed 'rule', the students were required to print out work for these folios, which in turn limited the types of activities which could be completed on the netbooks. Likewise, Wendy could not use online resources such as YouTube or Facebook due to established school policies preventing student access to social networking sites.

Three factors have been identified as contributing to the low level of usage: the lack of Technological Knowledge of the teachers in this study, when coupled with an increasing crowded curriculum and the historical ways that computers have been used in schools, resulted in an environment which made increased usage of computers, despite the increased level of access to computers, difficult for the teachers to accommodate into their practice.

\section{Conclusion and implications for policy and practice}

This study reported that, despite the provision of netbooks to enable one-to-one or one-to-two access, the usage of the netbooks was not substantial in terms of the actual student usage. The average daily use of each netbook was 61 minutes per day or $22.5 \%$ of the daily available time. However, this usage needs to be considered within the broader understanding that there were frequent interruptions to classroom learning due to non-contact time, school assemblies, rotational and extra-curricula activities. The net result of these disruptions is that the teachers in this school, and we suggest that this is likely in many primary schools, had approximately 12 hours per week, uninterrupted, with their 'home class'. Adjusting for this, the computers were used about $40 \%$ of the available 'home class' time in Classes A, C and D and over $60 \%$ of this time in Class B. The key finding here is that, although computer usage did not approach full time use, the increased availability of the netbooks provided greater flexibility and opportunity for the students to utilise the netbooks in ways which supported student engagement. The research into netbook usage in these classrooms provides useful implications for policy and practice, which are particularly pertinent in the current Australian education environment where the provision of one-to-one computing policies is a key component of government educational agendas. 
A key finding of this research was that netbook usage was greatest in the classrooms which had access to the computers in the one-to-two ratio. This challenges the assumption that one-to-one is the more desirable pattern of deployment. Based on these data, it may be a consideration that, in order to maximise usage of school resources, schools deploy the netbooks in a one-to-two rather than a one-to-one pattern. This decision has significant economic benefits to schools and may be particularly relevant in non-government primary schools as there is currently no direct government funding for the purchase of computers in these schools. In the case of the research school, the difference in purchasing one netbook for each student, as opposed to one between two, is in the order of $\$ 325,000$. Even if the devices were purchased only for students in Years 5-7, the difference between the provision of one-to-one computing and one-to-two computing would is over $\$ 100,000$. Such a cost versus use analysis also has implications for the current Digital Education Revolution, which will provide one-to-one computing access for every Australian student in Years 9-12. The study also outlined important educational implications of a one-to-two rather than one-to-one model of access, as well as these obvious economic, funding and resourcing implications. We argue that one-to-one computing decisions need to be informed by educational research. This study has contributed to the need for evidence-based approaches to inform the decision making related to one-to-one computing through the investigation of netbook usage by students provided with varying access to these devices.

\section{References}

Albion, P. (1999). Laptop orthodoxy: Is portable computing the answer for education. Australian Educational Computing, 14(1), 5-9. [verified 21 May 2011] http: / / acce.edu.au/journal / 14 / 1 / laptop-orthodoxy-portable-computing-answer-education

Bateman, D. \& Oakley, C. (2009). Research Report - The Classmate PC 1:1 eLearning Project in Australia. [verified 3 Jun 2010] http: / / managementofchange.wikispaces.com / file/ view / Classmate+PC+Australia+Pilot_+Deakin+Univ+Research+Report+Final+(2).pdf

Becker, H. (2000). Findings from the teaching, learning and computing survey: Is Larry Cuban right? Education Policy Analysis Archives, 8(51). [verified 21 May 2011] http: / / www.crito.uci.edu/tlc/ findings / ccsso.pdf

Buell, J. G. (2003). COWS in the classroom: Technology introduction and teacher change through the lens of activity theory. [not found 21 May 2011] http: / / www.ed.uiuc.edu/meter/Documents / COWS_FollowUp.pdf

Cuban, L. (2006). Commentary: The laptop revolution has no clothes. Education Week, 18 October, p. 29.

Dawson, K., Cavanaugh, C. \& Ritzhaupt, A. D. (2008/2009). Florida's EETT Leveraging Laptops initiative and its impact on teaching practices. Journal of Research on Technology in Education, 41(2), 143-159. http: / / www.eric.ed.gov:80/PDFS/ EJ826090.pdf

DEEWR (Department of Education, Employment and Workplace Relations (2008). Digital Education Revolution. http: / / www.deewr.gov.au/Schooling/DigitalEducationRevolution/Pages/default.aspx

Donovan, L., Hartley, K. \& Strudler, N. (2007). Teacher concerns during initial implementation of a one-to-one laptop initiative at the middle school level. Journal of Research on Technology in Education, 39(3), 263-286.

Dunleavy, M., Dexter, S. \& Heinecke, W. F. (2007). What added value does a 1:1 student to laptop ratio bring to technology-supported teaching and learning? Journal of Computer Assisted Learning, 23(5), 440-452. http: / / dx.doi.org/10.1111/j.1365-2729.2007.00227.x 
Ertmer, P. A. (1999). Addressing first- and second-order barriers to change: Strategies for technology integration. Educational Technology, Research and Development, 47(4), 47-61. http: / / dx.doi.org/ 10.1007/BF02299597

Finger, G. \& Sun, P.-C. (2010). The learning in the home: Importance and implications. In M. Lee \& G. Finger (Eds.), Developing a networked school community: A guide to realising the vision (pp. 73-84). Camberwell: ACER Press.

Franklin, C. (2007). Factors that influence elementary teachers use of computers. Journal of Technology and Teacher Education, 15(2), 267-293.

Gravelle, P. (2003). The Maine Learning Technology Initiative: Impact on the Digital Divide. [verified 21 May 2011] http:/ / www.usm.maine.edu/cepare/Reports/MLTI_Impact_Digital_Divide.pdf

Grimes, D. \& Warschauer, M. (2008). Learning with laptops: A multi-method case study. Journal of Educational Computing Research, 38(3), 305-332.

Gulek, J. C. \& Demirtas, H. (2005). Learning with technology: The impact of laptop use on student achievement. The Journal of Technology, Learning, and Assessment, 3(2). [verified 21 May 2011] http: / / escholarship.bc.edu / cgi/ viewcontent.cgi?article=1052\&context=jtla

Harris, W. \& Smith, L. (2004). Laptop use by seventh grade students with disabilities: Perceptions of special education teachers. [verified 21 May 2011] http: / / www.usm.maine.edu/cepare/Reports/MLTI_Report2.pdf

Hill, J. R. \& Reeves, T. C. (2002). The impact of portable technologies on teaching and learning: Year three report. [verified 21 May 2011] http: / / lpsl.coe.uga.edu/Projects / AAlaptop/pdf/EvalPropoal.pdf

Hounshell, P. B., Hill, S. \& Swofford, R. (2002). Using laptop computers to improve the performance of minority students: A pilot project. Journal of Science Education and Technology, 11(1), 101-103. http:/ / www.jstor.org/stable/40188601

Jamieson-Proctor, R., Finger, G. \& Albion, P. (2010). Auditing the TPACK capabilities of final year teacher education students: Are they ready for the 21st century? In Proceedings ACEC 2010: Digital Diversity Conference, Melbourne, April. http: / / acec2010.info/ sites / acec2010.info/ files / proposal/ 104/ acec2010final.pdf

Kuutti, K. (1996). Activity theory as a potential framework for human-computer interaction research. In B. Nardi (Ed.), Context and consciousness: Activity theory and human computer interaction (3rd ed., pp. 17-44). Cambridge: MIT Press.

Larkin, K. \& Finger, G. (2010). Investigating student netbook usage using activity theory. In Proceedings ACEC 2010: Digital Diversity Conference, Melbourne, April. http: / / acec2010.info/ sites/acec2010.info/ files / proposal/96/acec-2010larkinfingerinvestigating-student-netbook-usage.pdf

Lei, J. \& Zhao, Y. (2008). One-to-one computing: What does it bring to schools? Journal of Educational Computing Research, 39(2), 97-122.

Liang, J.-K., Liu, T.-C., Wang, H.-Y., Chang, B., Deng, Y.-C., Yang, J.-C., et al. (2005). A few design perspectives on one-on-one digital classroom environment. Journal of Computer Assisted Learning, 21, 181-189.

Lin, J. M.-C. \& Wu, Y.-J. (2010). Netbooks in sixth-grade English language classrooms. Australasian Journal of Educational Technology, 26(7), 1062-1074. http: / / www.ascilite.org.au/ajet/ajet26/lin.html

Lowther, D. L., Ross, S. M. \& Morrison, G. M. (2003). When each one has one: The influences on teaching strategies and student achievement of using laptops in the classroom. Educational Technology, Research and Development, 51(3), 23-44. [verified 21 May 2011]

http:/ / www.educ.msu.edu/epfp/ meet/01-2405files/when $\% 20$ each $\% 20$ one $\% 20$ has\%20one.pdf 
Mishra, P. \& Koehler, M. J. (2006). Technological pedagogical content knowledge: A framework for teacher knowledge. Teachers College Record, 108(6), 1017-1054.

Mouza, C. (2008). Learning with laptops: Implementation and outcomes in an urban, underprivileged school. Journal of Research on Technology in Education, 40(4), 447-473.

NCES (National Center for Education Statistics) (2000). Teachers' tools for the 21st Century. A report on teachers' use of technology. [verified 20 May 2011; $2.71 \mathrm{MB}$ ] http: / / nces.ed.gov/ pubs2000/2000102.pdf

Newhouse, C. P. (1997). Teachers' responses and classroom learning environments associated with student access to portable computers. Unpublished PhD, Curtin University of Technology, Perth. [verified 20 May 2011] http:/ / espace.library.curtin.edu.au:80/R?func=dbin-jumpfull\&local_base=gen01-era02\&object_id $=11804$

Newhouse, P.\& Rennie, L. (2001). A longitudinal study of the use of student-owned portable computers in a secondary school. Computers \& Education, 36(3), 223-243. http: / / dx.doi.org/10.1016/S0360-1315(00)00065-8

Onwuegbuzie, A. J. (2002). Why can't we all get along? Towards a framework for unifying research paradigms. Education, 122(3), 518 - 531.

Oxley, J. (2008). Open letter to Deputy Prime Minister Julie Gillard. QUick - Official Magazine of QSITE, 107, 23.

Penuel, W., Kim, D., Michalchik, V., Lewis, S., Means, B., Murphy, R., et al. (2002). Using technology to enhance connections between home and school: A research synthesis. Menlo Park, CA: SRI International. [verified 3 Jun 2011] http:/ / www.ctl.sri.com/publications/downloads/Task1_FinalReport3.pdf

Penuel, W. R. (2006). Implementation and effects of one-to-one computing initiatives: A research synthesis. Journal of Research on Technology in Education, 38(3), 329-349. http: / / business.highbeam.com/619/ article-1G1-143723979/implementation-and-effectsoneone-computing-initiatives

Ricci, C. (1999). Program evaluation: The New York City Board of Education Community School District Six Laptop Project. Paper presented at Tools and Transformations: The Community School District Six Laptop Project and Its Impact on Teachers and Students symposium, American Educational Research Association (AERA), Montréal, Canada, April 19-23. [verified 3 Jun 2011] http:/ / www.notesys.com/Copies/aeralptp.pdf

Rockman Et Al (1998). Powerful tools for schooling: Second year study of the Laptop Program. Rockman et al, San Francisco, CA. [verified 3 June 2011, 1.0 MB] http:/ / www.rockman.com/projects/126.micro.aal/yr2_report.pdf

Rockman, S. (2003). Learning from laptops. Threshold, 1(1), 24-28. [verified 3 Jun 2011] http:// www.rockman.com/publications/articles/LearningFromLaptops.pdf

Russell, M., Bebell, D. \& Higgins, J. (2004). Laptop learning: A comparison of teaching and learning in upper elementary classrooms equipped with shared carts of laptops and permanent one-to-one laptops. Journal of Educational Computing Research, 30(4), 313-330. http: / / baywood.metapress.com/app/ home/ contribution.asp?referrer=parent\&backto=issu e,4,7;journal,55,172;linkingpublicationresults,1:300321,1

Sarama, J., Clements, D. H. \& Henry, J. J. (1998). Network of influences in an implementation of a mathematics curriculum innovation. International Journal of Computers for Mathematical Learning, 3(2), 113-148. [verified 21 May 2011]

http: / / investigations.terc.edu/library/bookpapers/network_influences.cfm

Silvernail, D. L. \& Lane, D. M. M. (2004). The impact of Maine's one-to-one laptop program on middle school teachers and students. [verified 21 May 2011]

http: / / www.usm.maine.edu/ cepare/Reports/MLTI_Report1.pdf 
Stevenson, K. (1998). Evaluation report - Year 2: Schoolbook laptop project. Beaufort, SC: Beaufort County School District. [not found 21 May 2011]

http:// www.beaufort.k12.sc.us/district/ltopeval.html

Swan, K., Hooft, M. V. t., Kratcoski, A., \& Schenker, J. (2007). Ubiquitous computing and changing pedagogical possibilities: representations, conceptualizations and uses of knowledge. Journal of Educational Computing Research, 36(4), 481-515.

Swan, K., Hooft, M. v. t., Kratcoski, A. \& Unger, D. (2005). Uses and effects of mobile computing devices in K-8 classrooms. Journal of Research on Technology in Education, 38(1), 99-112.

Vannatta, R. \& Fordham, N. (2004). Teacher dispositions as predictors of classroom technology use. Journal of Research on Technology in Education, 36(3), 253-272. [verified 21 May 2011] http:// www.eric.ed.gov:80/ERICWebPortal/ contentdelivery/servlet/ERICServlet?accno=EJ690932

Weston, M. E. \& Bain, A. (2010). The end of techno-critique: The naked truth about 1-1 laptop initiatives and educational change. The Journal of Technology, Learning, and Assessment, 9(6), 625. [verified 21 May 2011] http:/ / escholarship.bc.edu/ cgi/viewcontent.cgi?article=1193\&context=jtla

Zucker, A. (2004). Developing a research agenda for ubiquitous computing in schools. Journal of Educational Computing Research, 30(4), 371-386.

Zucker, A. \& Hug, S. (2008). Teaching and learning physics in a 1:1 laptop school. Journal of Science Education and Technology, 17(6), 586-594. http: / / dx.doi.org/10.1007/ s10956-008-9125-3

Zucker, A. \& McGhee, R. (2005). A study of one-to-one computer use in mathematics and science instruction at the secondary level in Henrico County Public Schools. Washington, DC: SRI International. [verified 21 May 2011] http: / / ubiqcomputing.org/FinalReport.pdf

Authors: Dr Kevin Larkin (corresponding author)

Faculty of Education, Springfield Campus, University of Southern Queensland

Education City, Sinnathamby Boulevard, Springfield Central, QLD 4300

Email: Kevin.Larkin@usq.edu.au Web: http: / / apps.usq.edu.au/StaffSearch/

default.aspx?staffsearchaction=showdetails\&staffsearchrecordid $=3388$

Associate Professor Glenn Finger

School of Education and Professional Studies

Gold Coast Campus, Griffith University, Gold Coast Qld 4222

Email: G.Finger@griffith.edu.au Web: http:/ / www.griffith.edu.au/professionalpage/glenn-finger

Please cite as: Larkin, K. \& Finger, G. (2011). Informing one-to-one computing in primary schools: Student use of netbooks. Australasian Journal of Educational Technology, 27(3), 514-530. http:/ / www.ascilite.org.au/ajet/ ajet27/larkin.html

Errata 31 July 2011: p. 515. Change "4. Class D. Ratio of one-to-two..." to "4. Class D. Ratio of one-to-one...". 